\title{
Slowly progressive dementia caused by MAPT R406W mutations: longitudinal report on a new kindred and systematic review
}

Emil Ygland ${ }^{1}$, Danielle van Westen ${ }^{2 \dagger}$, Elisabet Englund ${ }^{3 \dagger}$, Rosa Rademakers ${ }^{4 \dagger}$, Zbigniew K. Wszolek ${ }^{5}$, Karin Nilsson ${ }^{1}$, Christer Nilsson ${ }^{1}$, Maria Landqvist Waldö ${ }^{6}$, rrina Alafuzoff ${ }^{7}$, Oskar Hansson ${ }^{8,9}$, Lars Gustafson ${ }^{1}$

and Andreas Puschmann ${ }^{1 *}$

\begin{abstract}
Background: The MAPT c.1216C > T (p.Arg406Trp; R406W) mutation is a known cause of frontotemporal dementia with Parkinsonism linked to chromosome 17 tau with Alzheimer's disease-like clinical features.

Methods: We compiled clinical data from a new Swedish kindred with R406W mutation. Seven family members were followed longitudinally for up to 22 years. Radiological examinations were performed in six family members and neuropathological examinations in three. We systematically reviewed the literature and compiled clinical, radiological, and neuropathological data on 63 previously described R406W heterozygotes and 3 homozygotes.
\end{abstract}

Results: For all cases combined, the median age of onset was 56 years and the median disease duration was 13 years. Memory impairment was the most frequent symptom, behavioral disturbance and language impairment were less common, and Parkinsonism was rare. Disease progression was most often slow. The most frequent clinical diagnosis was Alzheimer's disease. R406W homozygotes had an earlier age at onset and a higher frequency of behavioral symptoms and Parkinsonism than heterozygotes. In the new Swedish kindred, a consistent imaging finding was ventromedial temporal lobe atrophy, which was evident also in early disease stages as a widening of the collateral sulcus with ensuing atrophy of the parahippocampal gyrus. Unlike previously published R406W carriers, all three autopsied patients from the novel family showed neuropathological similarities with progressive supranuclear palsy, with predominant four-repeat (exon 10+) tau isoform (4R) tauopathy and neurofibrillary tangles accentuated in the basal-medial temporal lobe. Amyloid- $\beta$ pathology was absent.

Conclusions: Dominance of 4R over three-repeat (exon 10-) tau isoforms contrasts with earlier reports of R406W patients and was not sufficiently explained by the presence of $\mathrm{H} 1 / \mathrm{H} 2$ haplotypes in two of the autopsied patients. R406W patients often show a long course of disease with marked memory deficits. Both our neuropathological results and our imaging findings revealed that the ventromedial temporal lobes were extensively affected in the disease. We suggest that this area may represent the point of origin of tau deposition in this disease with relatively isolated tauopathy.

\footnotetext{
* Correspondence: andreas.puschmann@med.lu.se

${ }^{\dagger}$ Equal contributors

'Lund University, Skåne University Hospital, Department of Clinical Sciences

Lund, Neurology, Getingevägen 4, 22185 Lund, Sweden

Full list of author information is available at the end of the article
}

(c) The Author(s). 2018 Open Access This article is distributed under the terms of the Creative Commons Attribution 4.0 International License (http://creativecommons.org/licenses/by/4.0/), which permits unrestricted use, distribution, and reproduction in any medium, provided you give appropriate credit to the original author(s) and the source, provide a link to the Creative Commons license, and indicate if changes were made. The Creative Commons Public Domain Dedication waiver (http://creativecommons.org/publicdomain/zero/1.0/) applies to the data made available in this article, unless otherwise stated. 


\section{Background}

Tauopathies constitute a group of neurodegenerative disorders that include Alzheimer's disease (AD), progressive supranuclear palsy (PSP), Pick's disease, and others. These diseases are characterized by cerebral accumulation of the microtubule-associated protein tau [1]. Tau is composed of three- or four-microtubule binding domains, depending on alternative splicing of exon 10, leading to the threerepeat (exon 10-) tau isoform (3R) and the four-repeat (exon 10+) tau isoform (4R). Alternative inserts near the $\mathrm{N}$-terminus result in a total of six tau isoforms expressed under physiological circumstances [2]. Mutations in the gene encoding tau, $M A P T$, can lead to different clinical disorders and neuropathologies, which have been found to depend on the mutation's location within the gene [2]. Mutations in MAPT exons 9 and 11 and most mutations in exons 12 and 13 were associated with combined $3 \mathrm{R}$ and $4 \mathrm{R}$ tau pathology. Several mutations in exon 10 and all of the $5^{\prime}$ following intronic mutations inhibit alternative exon 10 splicing, leading to predominant $4 \mathrm{R}$ tau deposition in neurons as well as glial cells. Other MAPT mutations, including MAPT c.1216C $>\mathrm{T} \quad$ (p.Arg406Trp; $\mathrm{R} 406 \mathrm{~W}$ ) in exon 13, however, did not affect the ratio of $3 \mathrm{R}$ to $4 \mathrm{R}$ tau isoforms in laboratory models, but they caused aggregations of all six forms of tau, more closely resembling the situation in $\mathrm{AD}$ [2]. Clinical symptoms in patients with MAPT mutations are generally heterogeneous and designated as frontotemporal dementia with Parkinsonism linked to chromosome 17 (FTDP-17 MAPT $_{\text {}}$ ). Patients with R406W develop clinical features of both AD and FTDP-17 [3] and have brain deposition of tau as neurofibrillary tangles (NFTs), whereas amyloid- $\beta$ (A $\beta$ ) pathology is only rarely present [4-6]. This makes FTDP$17_{\mathrm{R} 406 \mathrm{~W}}$ an ideal candidate for studying human tau-only pathology.

In this study, we identified R406W in a large Swedish family with slowly progressive dementia. We present longitudinal radiological and clinical data derived from this novel kindred, including the neuropathology of three patients who died after various disease durations. We also systematically reviewed previously described R406W patients, aiming for a firmer determination of the typical clinical features of FTDP-17 $7_{\text {R406w }}$. However, in contrast to previous results, all three neuropathologically examined members of the family in the present study showed PSP-like neuropathology with clear predominance of $4 \mathrm{R}$ over $3 \mathrm{R}$ tau.

\section{Methods}

\section{Description of a new kindred}

In 1987, the kindred's proband (III-2) approached one of the authors (LG) because several family members had developed dementia. Family members were contacted after genealogical research in publicly available databases or through the proband, and symptomatic patients were enrolled. Seven affected family members (the proband and patients III-3, III-4, III-5, III-6, IV-9, and IV-16) were followed longitudinally for up to 22 years and were repeatedly examined by a specialist in memory disorders or neurology (LG, CN, or AP). Clinical data, including medical history, neurological and neuropsychiatric assessments, cerebrospinal fluid (CSF) analyses, and apolipoprotein E genotype were collected and compiled. For the other affected members, clinical data as provided by the family were collected.

\section{Genetic analyses}

Blood was collected from a total of 14 family members, and DNA was extracted using standardized methods. Four affected family members (III-2, III-3, III-6, and IV9) were examined by exome sequencing. Other samples were analyzed with TaqMan genotyping assays (Applied Biosystems, Foster City, CA, USA).

\section{Imaging}

Data on radiological examinations of affected family members performed during the course of the study and at admission were compiled and included computed tomography $(\mathrm{CT})$ and magnetic resonance imaging results. Images were reevaluated in this research study by a neuroradiologist (DvW). Medial temporal atrophy was visually rated using the Scheltens (visual) rating scale [7]. White matter hyperintensities, a common manifestation of small vessel disease, was quantified using the Fazekas scale [8].

\section{Neuropathology}

Autopsy was performed in three family members. Individual III-1 had died in the 1980s of colorectal cancer, and only four small tissue blocks of brain tissue were still available. In individuals III-3 and III-6, full-scale neuropathological examination was performed (by EE) [9]. These brains were assessed macroscopically for regional atrophy and for vascular or other focal pathology, then cut into coronal whole-brain sections as well as into small samples comprising frontal, parietal, temporal, and occipital lobe cortices and white matter, central brain nuclei, limbic structures, brainstem, and cerebellum. After dehydration and paraffin-embedding, the blocks were sectioned at 5- and 4- $\mu \mathrm{m}$ thickness (large and small sections, respectively). Sections from all patients were then stained with conventional stains such as H\&E and Luxol fast blue and counterstained with cresyl violet, stains for detection of protein deposits (modified Gallyas silver) and for $\mathrm{A} \beta$ (Congo red), as well as immunohistochemical stains targeting hyperphosphorylated tau (AT8; Dako, Glostrup, Denmark), tau isoforms 3R and 4R (anti-tau 3-repeat isoform RD3, 8E6/C11; EMD 
Millipore, Billerica, MA, USA; and anti-4R-tau, catalogue number TIP-4RT-P01; Cosmo Bio, Tokyo, Japan), $\alpha$-synuclein (Zymed Laboratories, South San Francisco, CA, USA), and TAR DNA-binding protein (pTDP-43; Cosmo Bio). The tau sections were examined independently by two neuropathologists (EE and IA).

\section{Systematic review}

A systematic review of the R406W literature was performed by searching the PubMed database (latest search date 24 February 2017). Search terms used were "tau", "MAPT" or "Microtubule associated protein tau" in all possible combinations with "R406W", "Arg406Trp", "406", "1216", "1216C > T" and "1216C-T". We included only peer-reviewed publications written in English. Reference lists of the retrieved studies were searched. Case reports and patient series regarding humans with R406W including clinical, radiological, or pathological data were selected for review by reviewing titles and abstracts, as well as, when there was uncertainty, full text. When there were several publications on the same kindred, individual information could be linked to the corresponding family member using data from pedigrees, clinical milestones, or personal communication with the authors. Individuals with no additional data than mutation status were excluded. When particular variables were not reported in a publication, this was marked in the resulting tables. Only descriptive nonparametric statistics were used.

\section{Results}

\section{Description of a new Swedish kindred}

Exome sequencing revealed an R406W mutation in patients III-3, III-6, and IV-9. This mutation was subsequently identified in all other affected family members for whom DNA was available, except the proband (III-2) who had developed dementia during the course of this study but in whom the mutation was excluded. The proband III-2 had onset of memory impairment at the age of 75 , which was later than in the other affected family members (Table 1). He was diagnosed with AD 2 years later and did not develop marked behavioral problems or Parkinsonism and was therefore considered to have sporadic $\mathrm{AD}$ and was excluded from the study. All other family members who did not carry the mutation were clinically unaffected. Four affected family members for whom no DNA was available were obligate mutation carriers (Fig. 1).

Individual clinical information from the other members of this family (those with the R406W mutation) is compiled in Table 1. Median age of onset was 55 (IQR 51.25-61.75) years, and median disease duration, excluding patient III-1 because her cause of death (colorectal cancer) was considered unrelated to the disease, was 14
(IQR 9-26) years. Memory impairment was a marked symptom in all R406W carriers. Behavioral symptoms were present in all these family members but were mostly predominant in later disease stages and remained mild in several individuals. Other symptoms in this family included confabulation, déjà vu, substance abuse, impaired visuospatial functioning, and wandering behavior. Disease progression was slow (Table 1), and individuals III-3, III-4, III-5, and III-6 did not move to a nursing home until 20,11,14, and 24 years after symptom onset, respectively. These four family members also retained the ability to play musical instruments up to 22 years after symptom onset. According to family history, individuals I-1 and I-2 both developed dementia with an escape-prone behavior and had been cared for at a community center for the elderly. Individual II-1 had slowly progressing memory deficits.

Patient III-6 was treated with cholinesterase inhibitors (ChEIs) for 17 years. Treatment effect was uncertain, although further clinical deterioration was documented after ChEI discontinuation. Combination with memantine was discontinued a few weeks after initiation, possibly owing to side effects. Individuals IV-9 and IV-16 have recently begun ChEI treatment.

\section{Imaging}

Radiological examinations were performed in six family members, with longitudinal data available from three (Fig. 2). Median disease duration at examination was 6 (IQR 2-20) years in our 6 novel cases compared with 6 (IQR 1-12.25) years for the 23 reviewed cases (Table 2). A pattern was observed in the ventromedial temporal lobe (VMTL) in five family members, characterized by atrophy of the parahippocampal gyrus (PHG) with marked widening of the collateral sulcus (CS). The pattern was observed shortly after symptom onset and progressed over time (Fig. 2). Hippocampal atrophy was present in four family members but less pronounced than PHG atrophy. Thus the temporal atrophy in these patients differed from the typical pattern in $\mathrm{AD}$, where medial temporal lobe atrophy primarily involves the hippocampus with widening of the choroid fissure. In addition, there was general atrophy that increased over time and may be related to both age and disease duration. Individuals IV-9 and III- 1 had L $>R$ asymmetric lateral temporal lobe atrophy reminiscent of semantic dementia (SD).

Individuals IV-9, IV-16, and III-6 of this study have been examined by ${ }^{18} \mathrm{~F}-\mathrm{AV}-1451$ tau-positron emission tomography (PET) in another study revealing tracer uptake in frontotemporal areas and the hippocampus [9].

\section{Neuropathology}

Autopsy of patient III-3, who died after 27 years of disease (brain weight $940 \mathrm{~g}$ ), macroscopically showed 


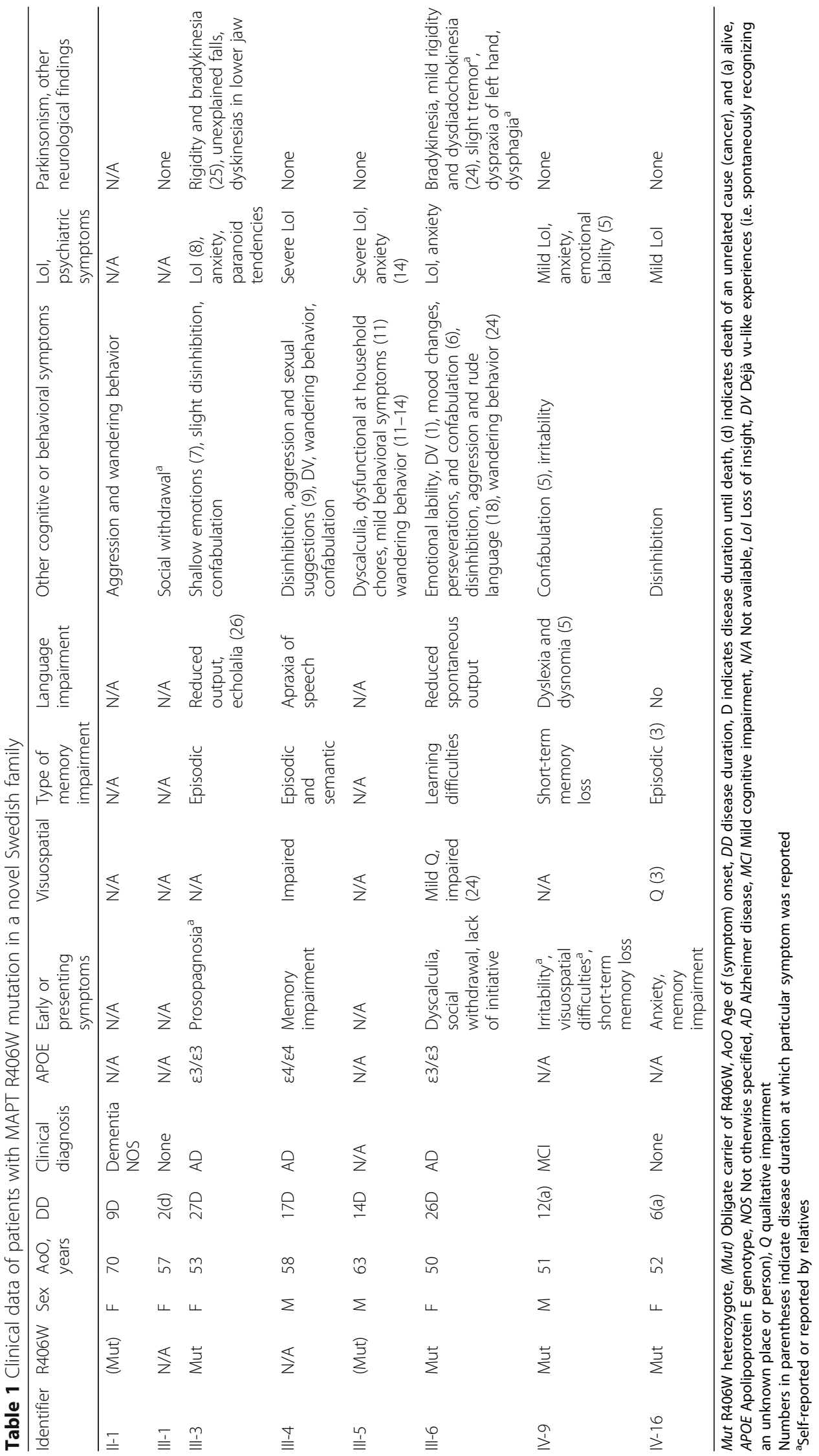



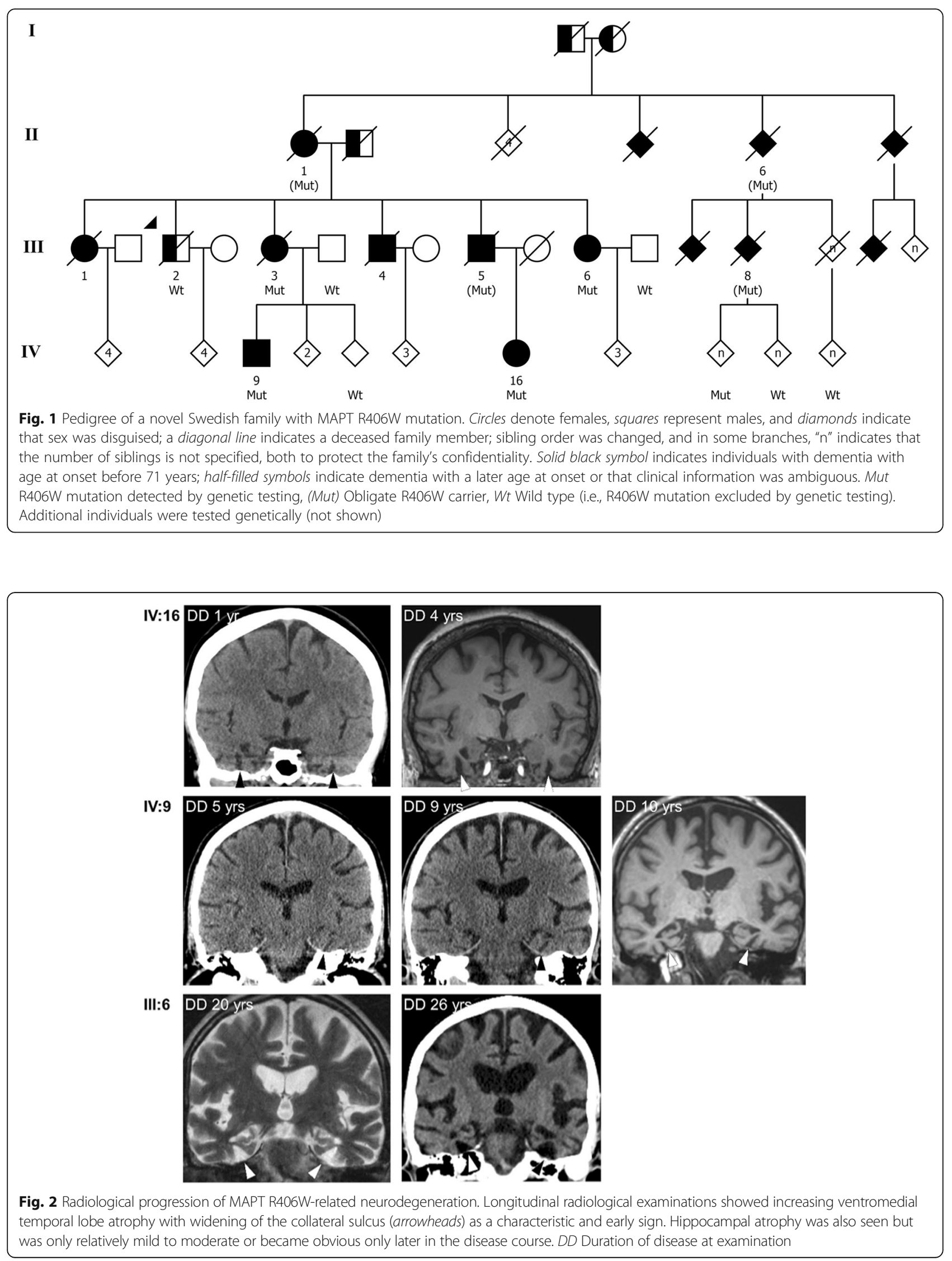


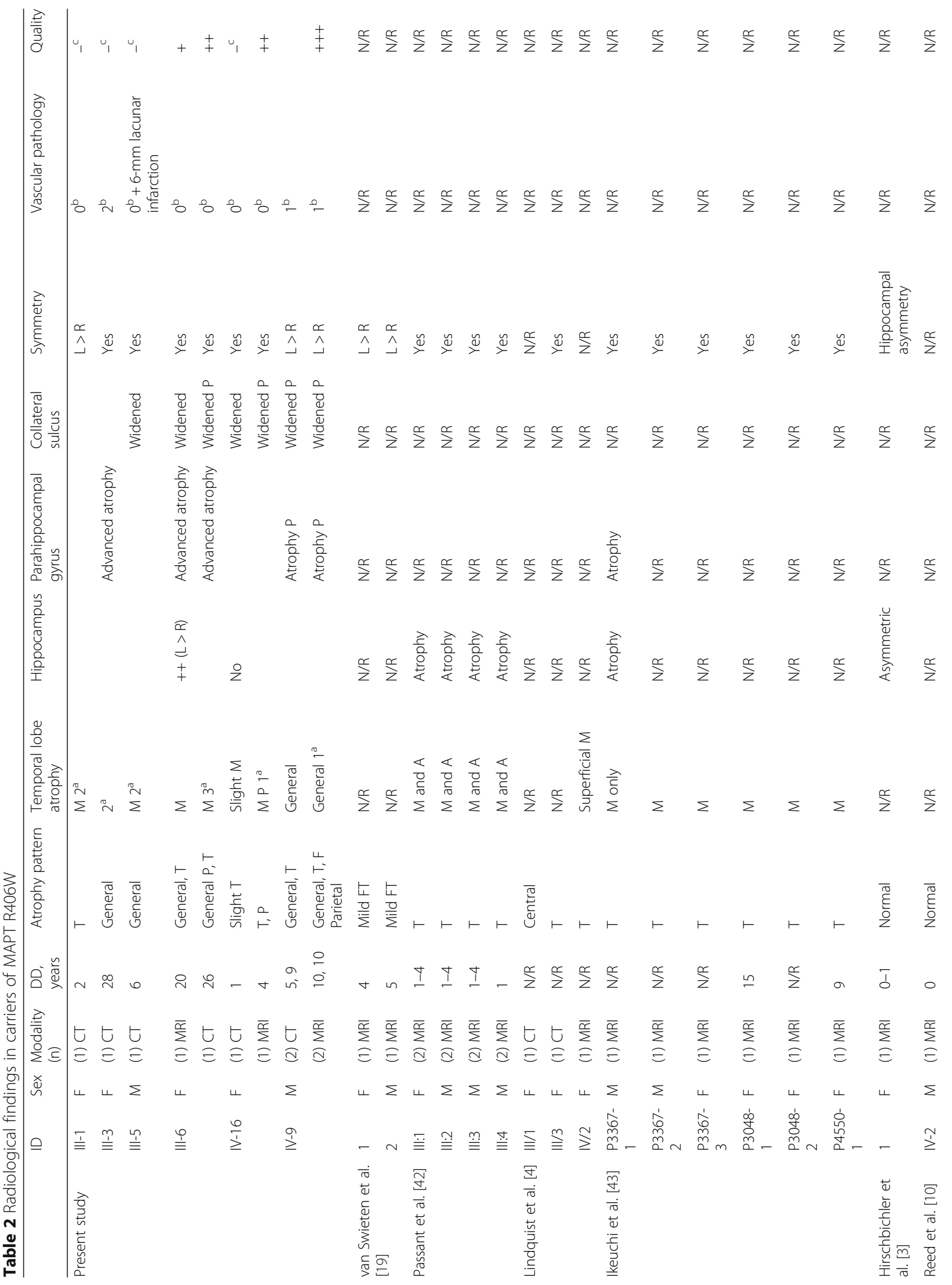




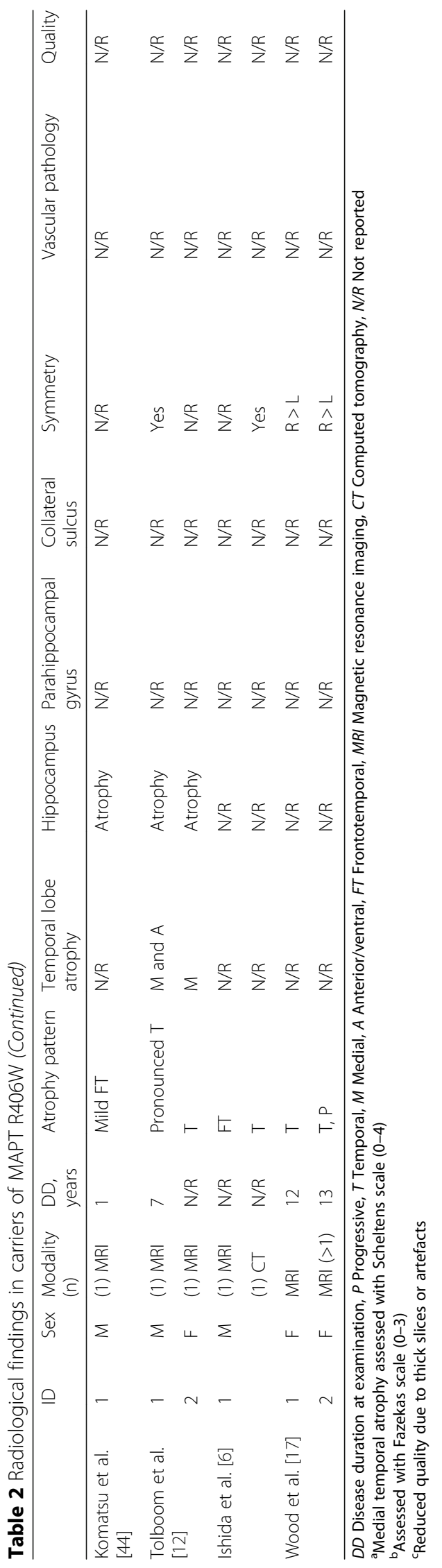


atrophy in the frontal lobes and more severe atrophy bitemporally, especially pronounced in the PHG, accompanied by a marked dilation of the IIIrd and IVth ventricles, as a sign of atrophy within the region of central nuclei and the brainstem, respectively. The hippocampus exhibited severe atrophy, with a remaining size of $4 \times 2$ $\mathrm{mm}$ in the midhippocampal region, coronal plane. Microscopically, there was severe cortical degeneration with neuronal loss and gliosis in the VMTL, including the entorhinal region, where it was most marked in the PHG, creating a markedly widened CS. The amygdala was degenerated, whereas within the hippocampus, the overall severe cell loss was accentuated in Cornu Ammonis (CA)1. There was marked neuronal loss and gliosis of basal ganglia, most pronounced in the globus pallidus. The insular cortex, the thalamus, and the subthalamic nucleus harbored significant tau pathology. Brainstem nuclei were markedly degenerated with cell loss and depigmentation, especially the locus coeruleus and substantia nigra.

Immunoreactivity against hyperphosphorylated tau was intensive in all the areas examined where there was neuronal loss, and there were abundant silver-positive NFTs (Table 3). There was marked white matter degeneration also in the temporal lobe, with widespread taupositive axonal fragments. In this individual, TDP-43 immunoreactivity was seen, appearing as large cytoplasmic granular inclusions in neurons; fewer but otherwise similar inclusions were present in glial cells in the gray matter and in the white matter.

The neuropathology of patient III-6, who died after 26 years of disease (brain weight $1085 \mathrm{~g}$ ), revealed atrophy in the frontal and temporal lobes, more markedly in the latter, as well as dilation of the third and fourth ventricles and atrophy of the brainstem, similar to the macroscopic findings of patient III-3. Microscopically, there was neuronal loss and gliosis in a distribution pattern similar to that of patient III-3, with the majority of pathological changes seen in the basal temporal lobes, including the hippocampus, the central nuclei, and the brainstem nuclei. Also in this patient, there was involvement of cerebral white matter. Tau immunoreactivity was marked owing to NFTs in cortical neurons, the thalamus, PHG, and hippocampi (especially in the dentate fascia), and there were some tufted astrocytes. In the white matter, there were tau-positive depositions in neurites, axonal fragments, and some glial inclusions. The tau-immunoreactive changes were most pronounced in the temporal lobes, clearly evident in the frontal lobes and basal ganglia, less pronounced in the parietal and occipital lobes, and only sparsely in the cerebellum. There was focal $\alpha$-synuclein-positive pathology with Lewy bodies and Lewy neurites, regionally confined to the hippocampal CA2, where there also was pyramidal cell loss.
Patient III-1 died of colon adenocarcinoma 2 years after onset of memory problems. There were no metastases to the brain. Autopsy was performed in the 1980s. The limited tissue blocks available for reassessment in the present study did not allow a comparison with the areas of maximal macroscopic atrophy on imaging, but they exhibited mild neuronal degeneration in sections representing the midbrain and neocortex (specific area not known). These areas stained densely positive for tau, as did the subjacent white matter.

All three patients assessed neuropathologically had abundant $4 \mathrm{R}$ pathology in cells and dystrophic neurites, as well as much less intense and less widespread 3R immunohistochemical staining positivities, which were confined to a few neurons (Fig. 3 and Additional file 1). No brain $A \beta$ was detected. There were many globose NFTs in the cortex, and in patients III-3 and III-6, globose NFTs were also noted in the hippocampus, as well as many tau-positive axonal fragments in the white matter, but there was a less prominent appearance of tufted astrocytes and fewer coiled bodies.

Among the autopsied family members, both III-3 and III-6 carried the $\mathrm{H} 1 / \mathrm{H} 2$ tau haplotype. No DNA was available for the third autopsied individual, III-1. Patient IV-9 also showed H1/H2 (Additional file 2).

\section{Systematic review}

Clinical data on 66 R406W patients were compiled from the literature (Table 4, and Additional files 3 and 4 for individual clinical data and cerebrospinal fluid examinations). The reports were published between 1997 and 2017, and methods of ascertainment, patient evaluation, and reporting varied. Median age of onset was 55.5 (IQR 51.25-59.75) years, and median disease duration reported at last examination or death was 13 (IQR 11-21) years. Onset of memory impairment was reported as early in $59 \%$ of the reviewed cases. Onset of visuospatial impairment was in the first years of disease for two patients [10, 11] and reported as gradual in four additional patients [11]. Behavioral symptoms developed in $42.4 \%$, but Parkinsonism developed in only $16.7 \%$ of reviewed cases. These symptoms were present at disease onset in only $22.7 \%$ and $4.5 \%$ of the reviewed cases, respectively. Prosopagnosia was reported to have occurred 7 and 24 years after symptom onset in two reviewed cases $[10,12]$. Reported R406W homozygotes had much earlier symptom onset and earlier and more pronounced behavioral symptoms and Parkinsonism; one homozygous patient also had paranoid delusions, hyperreligiosity, and compulsive behavior $[13,14]$.

Radiological and neuropathological data of previously described cases were compiled (Tables 2 and 3). Stabilized clinical progression and positive fludeoxyglucosePET measurement was reported in one patient after 
Table 3 Neuropathological features of MAPT R406W patients

\begin{tabular}{|c|c|c|c|c|c|c|c|c|}
\hline Kindred & $\begin{array}{l}\text { Patient } \\
\text { (DD) }\end{array}$ & Neuronal tau & Glial tau & $\begin{array}{l}\text { Ultrastructure } \\
\text { of tau } \\
\text { filaments }\end{array}$ & $\begin{array}{l}\text { Tau biochemistry/ } \\
\text { isoforms }\end{array}$ & Amyloid & a-Synuclein & Interpretation \\
\hline $\begin{array}{l}\text { Midwest } \\
\text { American/ } \\
\text { FTD004 family } \\
{[10,31,32,34]}\end{array}$ & $1(30)$ & $\begin{array}{l}\text { NFT, NT, } \\
\text { globose } \\
\text { tangles }\end{array}$ & $\begin{array}{l}\text { Occasional } \\
\text { astrocytes } \\
\text { (tangle-like } \\
\text { inclusions) }\end{array}$ & PHF & $\begin{array}{l}\text { Six fractions; both wild- } \\
\text { type and mutated tau } \\
\text { in deposits }\end{array}$ & None & & PSP \\
\hline \multirow[t]{2}{*}{$\begin{array}{l}\text { Dutch family [5, } \\
19,31,33,45]\end{array}$} & $1(13)$ & $\begin{array}{l}\text { NFT, some } \\
\text { pretangles, } \\
\text { dystrophic } \\
\text { neurites, NT, a } \\
\text { few PB }\end{array}$ & $\begin{array}{l}\text { Occasional glial } \\
\text { cells }\end{array}$ & PHF and SF & $\begin{array}{l}3 R \text { and } 4 R \text { isoforms; } \\
\text { both wild-type and mu- } \\
\text { tated tau in deposits, } \\
4 R<3 R\end{array}$ & $\begin{array}{l}\text { DP (low } \\
\text { density), no } \\
\text { congophilic } \\
\text { plaques, no } \\
\text { angiopathy }\end{array}$ & None & \\
\hline & $2(13)$ & $\begin{array}{l}\text { NFT, NT, } \\
\text { diffuse/ } \\
\text { amorphous } \\
\text { cytoplasmic } \\
\text { tau deposits }\end{array}$ & None & $\begin{array}{l}\text { PHF as in } A D, \\
\text { and SF } \\
\text { (minority of } \\
\text { filaments) }\end{array}$ & $\begin{array}{l}3 R \text { and } 4 R \text { isoforms; six } \\
\text { fractions; both wild- } \\
\text { type and mutated tau } \\
\text { in deposits, ghost } \\
\text { tangles }\end{array}$ & $\begin{array}{l}\text { NP (moderate } \\
\text { density) }\end{array}$ & & \\
\hline $\begin{array}{l}\text { Japanese family } \\
1 \text { [46] }\end{array}$ & 1 & NFT, NT & $\begin{array}{l}\text { Oligodendroglial } \\
\text { coiled bodies } \\
\text { (only Gallyas- } \\
\text { Braak staining } \\
\text { reported) }\end{array}$ & N/A & $\begin{array}{l}\text { Both wild-type and mu- } \\
\text { tated tau in deposits; } \\
\text { widespread ghost } \\
\text { tangles }\end{array}$ & None & None & $\begin{array}{l}\text { Features of } \\
\text { PSP/CBD/ } \\
\text { tangle-only } \\
\text { dementia }\end{array}$ \\
\hline $\begin{array}{l}\text { U.S. family } 2 \\
\text { [35] }\end{array}$ & 1 & $\begin{array}{l}\text { NFT, NT, no } \\
\text { PB }\end{array}$ & None & N/A & $3 R$ and $4 R$ isoforms & None & No LB & $\begin{array}{l}\text { NFT } \\
\text { dementia }\end{array}$ \\
\hline $\begin{array}{l}\text { Danish family } \\
{[4]}\end{array}$ & 1 & $\begin{array}{l}\text { NFT, NT, no } \\
\text { PB }\end{array}$ & $\begin{array}{l}\text { Occasional glial } \\
\text { cells (fibrillary } \\
\text { inclusions) }\end{array}$ & N/A & $\begin{array}{l}3 R \text { and } 4 R \text { isoforms; } 4 R \\
<3 R\end{array}$ & $\begin{array}{l}\text { NP (CERAD A); } \\
\text { many DP }\end{array}$ & None & \\
\hline $\begin{array}{l}\text { Japanese family } \\
2 \text { [6] }\end{array}$ & 1 & $\begin{array}{l}\text { NFT, NT, PB- } \\
\text { like inclusions } \\
\text { (or globose } \\
\text { tangles) }\end{array}$ & $\begin{array}{l}\text { Cytoplasmic } \\
\text { immunoreactivity } \\
\text { in glia }\end{array}$ & N/A & $\begin{array}{l}4 R<3 R \text { isoforms; } 3 R- \\
\text { positive ghost cells }\end{array}$ & $\begin{array}{l}\text { NP (CERAD C); } \\
\text { many DP }\end{array}$ & & \\
\hline $\begin{array}{l}\text { U.S. family } 3 \\
\text { (ZKW, personal } \\
\text { communication) }\end{array}$ & $1(29)$ & NFT, NT & & N/A & $3 R$ and $4 R$ isoforms & NP & & $A D$ \\
\hline U.K. patient [17] & 1 & NFT, PB & $\begin{array}{l}\text { Astrocytic } \\
\text { plaques }\end{array}$ & $N / R$ & $N / R$ & $N / R$ & $N / R$ & $N / R$ \\
\hline \multirow[t]{3}{*}{$\begin{array}{l}\text { Swedish family } \\
\text { (present report) }\end{array}$} & III:1 (2) & $\begin{array}{l}\text { NFT, NT, } \\
\text { neurites }\end{array}$ & Tufted astrocytes & N/A & $4 R>3 R$ & None & None & $\begin{array}{l}\text { PSP-like } \\
\text { dementia } \\
\text { (minimal } \\
\text { material) }\end{array}$ \\
\hline & III:3 (27) & $\begin{array}{l}\text { NFT, NT, } \\
\text { neurites }\end{array}$ & $\begin{array}{l}\text { Tufted astrocytes, } \\
\text { glial plaques }\end{array}$ & N/A & $4 R>3 R$ & None & None & $\begin{array}{l}\text { PSP-like } \\
\text { dementia }\end{array}$ \\
\hline & III:6 (26) & $\begin{array}{l}\text { NFT, NT, } \\
\text { neurites }\end{array}$ & Tufted astrocytes & N/A & $4 R>3 R$ & None & $\begin{array}{l}\text { Minimal } \\
\text { (focal in } \\
\text { CA2) }\end{array}$ & $\begin{array}{l}\text { PSP-like } \\
\text { dementia }\end{array}$ \\
\hline
\end{tabular}

$A D$ Alzheimer's disease, $3 R$ tau Three-repeat (exon 10-) tau isoform, $4 R$ tau Four-repeat (exon 10+) tau isoform, CA Cornu Ammonis area, CERAD Consortium to Establish a Registry for Alzheimer's Disease, DD Duration of disease, PHF Paired helical filaments, SF Straight filaments, NFT Neurofibrillary tangles, NT Neutrophil threads, PB Pick bodies, NP Neuritic plaques, DP Diffuse plaques, Six fractions All six insoluble tau fractions detected, CBD Corticobasal dementia, $L B$ Lewy bodies

memantine treatment [4]. Neuropathological examination was performed in nine reviewed cases. Four had tau-only pathology, but five showed co-occurring $A \beta$ pathology, including several cases with observed concomitant positive immunohistochemistry for $A \beta$ and ubiquitin (Table 3).

\section{CSF examinations}

Results of CSF examinations were available for three members of the novel Swedish kindred and six reported cases in the literature and showed a trend for increased levels of CSF tau and phosphorylated tau in about half of R406W patients, but normal levels of CSF $A \beta_{1-42}$ (Additional file 4).

\section{Discussion}

We present a novel Swedish R406W kindred with markedly slowly progressive dementia, as well as a systematic review of previous reports on FTDP$17_{\mathrm{R} 406 \mathrm{~W}}$ patients. The clinical phenotype of patients 


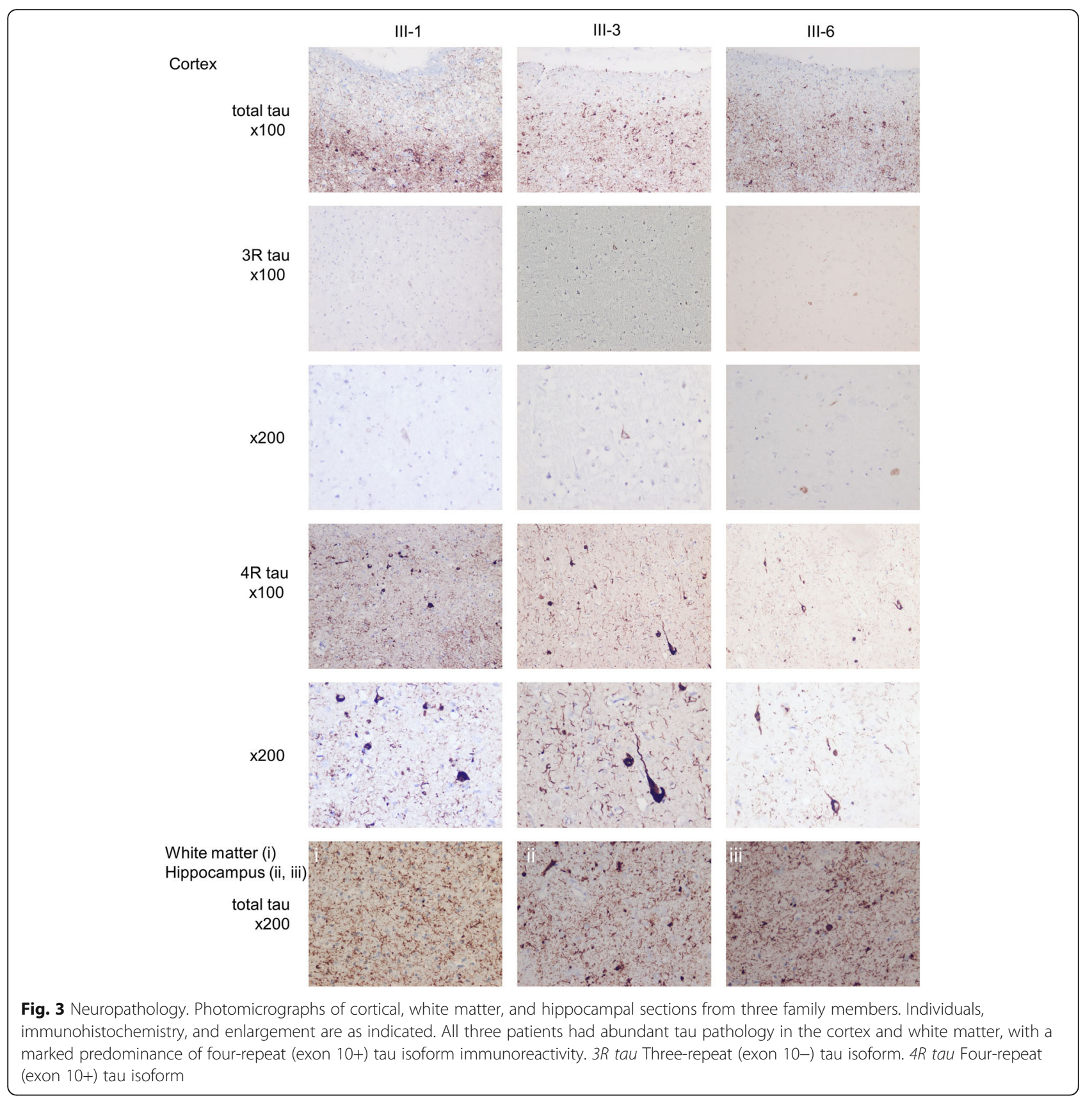

with this mutation consists predominantly of memory loss and varying or gradual development of frontotemporal dementia (FTD)-like cognitive dysfunction. Radiological examinations of FTDP-17 $7_{\mathrm{R} 406 \mathrm{~W}}$ patients reveal progressing atrophy that starts in the VMTL and spreads to adjacent regions over time. Neuropathology shows a pattern of regional degeneration and accumulation of NFTs. Although previously reported individuals with this mutation had both $3 \mathrm{R}$ and $4 \mathrm{R}$ tau pathology, all three autopsied members of the present family had a PSP-like pathology, with a regional spread of degeneration and with marked predominance of $4 \mathrm{R}$ over $3 \mathrm{R}$, but without some of the other PSP-characteristic traits.

\section{Limitations}

The major limitation of this study is the small size of our cohort and the low quantity of verified R406W cases in the literature. The review might be influenced by publication or selection biases as well as differences in reporting and grading of symptoms between authors. A common problem with neurogenetic diseases is the rarity of specific point mutations 


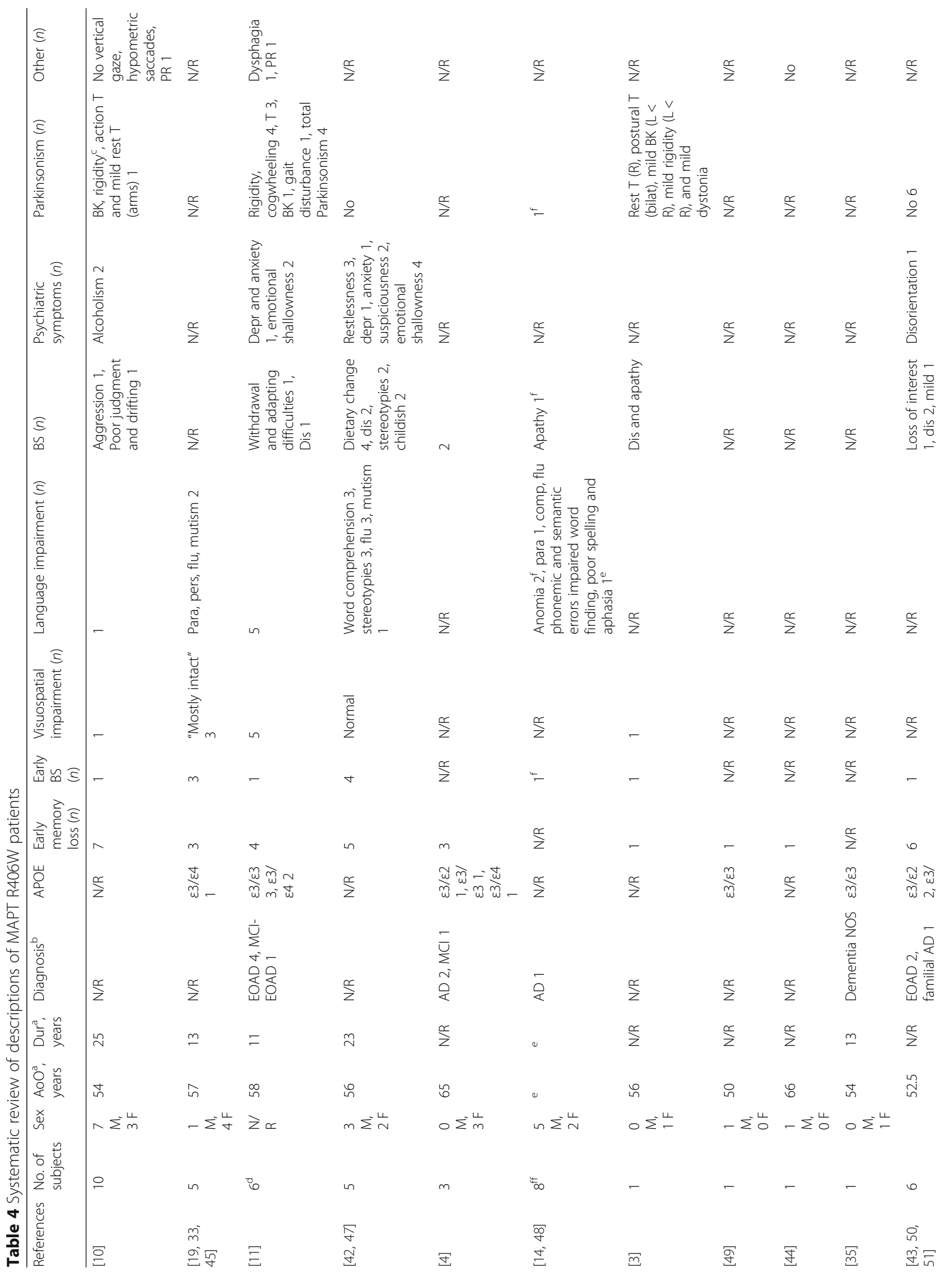




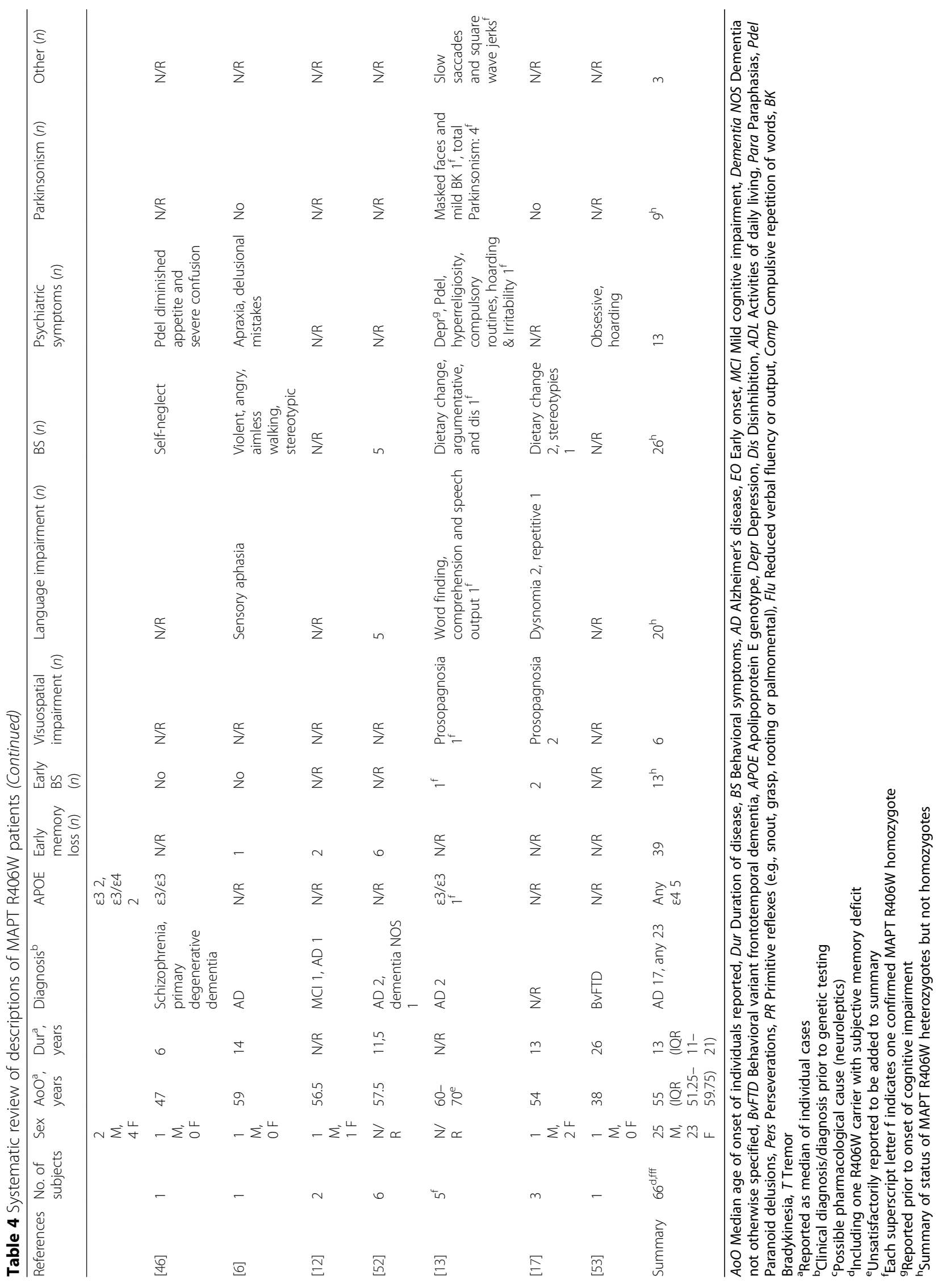


[15]. This is an important issue because larger cohorts will probably be needed to explain the observed and not yet fully understood clinical heterogeneity of patients with $M A P T$ mutations.

\section{Clinical features}

Although there is large intra- and interfamilial clinical variability in all FTDP-17 MAPT $_{\text {[2], R406W patients }}$ often first develop memory impairment. Parkinsonism occurred rarely at end-stage disease in the novel Swedish family, and many patients in this and other families with FTDP-17 $7_{\text {R406W }}$ received an initial clinical diagnosis of AD. Disease progression was remarkably slow (Tables 1 and 2), and age of onset is later than for patients with most other MAPT mutations [2]. In the novel Swedish family, déjà vu and confabulation, previously described in dementia cases with predominant temporal lobe atrophy [16], developed in $50 \%$ of cases. As the disease progressed, more symptoms typically associated with FTD developed, such as disinhibition, wandering behavior, and aggression. More severe disease was present in all of the more recently described homozygous R406W patients, suggesting a dose-dependent and direct effect of R406W mutated tau [13, 14].

\section{Radiological features}

Atrophy in our novel R406W cases was initially seen in the VMTL, with atrophy of the PHG and secondary widening of the CS as a consistent, early, and progressive pattern. Throughout the disease course of these patients, VMTL atrophy remained more pronounced than hippocampal atrophy, which was observed only late. Thus, the pattern of atrophy in our R406W cases differed from the typical AD pattern. Any assessment of diagnostic or prognostic value of this finding was considered beyond the scope of this work, and confirmation is needed. We suggest, however, that relatively isolated PHG atrophy and CS widening should raise suspicion of FTDP-17 $7_{\mathrm{MAPT}}$ and especially FTDP- $17_{\mathrm{R} 406 \mathrm{~W}}$. Because radiologists may tend to describe either medial or lateral temporal lobe atrophy, and because neither atrophy of the PHG nor associated widening of the CS is incorporated in the Scheltens (visual) rating scale [7], there may be underreporting of more predominant VMTL atrophy, and/or localized changes affecting only CS or PHG, in other tauopathies.

FTDP-17 $17_{\text {R406W }}$ disease can sometimes manifest with asymmetric temporal lobe atrophy [17], and left (dominant) lateral temporal lobe atrophy has rarely been reported in FTDP-17 $7_{\text {R406W }}$ patients $[2,18,19]$. Clinical SD symptoms in addition to FTD phenotype, however, have been more commonly reported in FTDP-17 patients with other MAPT mutations [20]. Temporal lobe atrophy with leftsided dominance, as in SD, was found radiologically in patients III-1 and IV-9. The unrelated and early death of patient III-1 prevented detailed characterization of clinical symptoms, but patient IV-9 had dysnomia and misunderstood or forgot instructions despite relatively short disease duration. This supports the possibility of an SD-similar phenotype in FTDP-17 1 R406W .

This is the first study to report mainly $4 \mathrm{R}$ tau pathology in FTDP-17 $17_{\text {R406W }}$ patients, which contrasts with previous findings [2]. It has been suggested that the pattern of temporal lobe atrophy differs, depending on the location of the MAPT mutation, with regard to the effect on exon 10 alternative splicing [21]. Medial temporal lobe atrophy is found more often in patients with IVS10 + 3, IVS10 + 16, p.N279K, and p.S305N mutations, which affect exon 10 splicing and lead to expression of only $4 \mathrm{R}$ tau. Lateral temporal lobe atrophy was reported in p.P301L and p.V337M cases, where both $3 \mathrm{R}$ and $4 \mathrm{R}$ tau are expressed $[2,21]$.

\section{Neuropathological features}

In the novel Swedish family, individuals III-1, III-3, and III-6 had tau depositions in cortical neurons and in white matter, which were most pronounced in the temporal lobe. In particular, the widening of the CS, as seen with imaging, prevailed as a prominent detail also demonstrated postmortem (Additional file 1). The temporolimbic region was thus particularly affected (when available for neuropathological examination; patient III-3 and III-6), and furthermore, the locus coeruleus had a high tau load and was highly atrophic. These findings are consistent with the clinical similarities between R406W-associated disease and AD. In the hippocampi of patients III-3 and III-6, CA1 neurons were severely affected, similar to both PSP and AD. The severity of the central atrophy exceeded that seen in other tauopathies, except in severe forms of PSP. This unequally spread atrophy might stand for a slow and unique distribution of pathology caused by R406W mutated tau.

Immunohistochemical staining in the novel family showed the presence of both $3 \mathrm{R}$ and $4 \mathrm{R}$ tau isoforms. However, $4 \mathrm{R}$ tau staining was clearly more abundant, and $3 \mathrm{R}$ tau was judged to be at nearly physiological levels for age (Fig. 3). The pathological picture in the Swedish family was reminiscent of PSP also in aspects other than $4 \mathrm{R}$ predominance: (1) the presence of neuronal NFTs and, albeit scarce, of tufted astrocytes and occasional coiled bodies [22, 23]; (2) prominent tau white matter pathology, and (3) marked involvement of the brainstem and central nuclei. However, the cortical load of tau-positive threads and neurons was more dense and severe than seen in typical PSP [22]. This may hypothetically be an effect of the disease process allowed to develop during an unusually long time. Hereditary PSP is rare, but families with more than one member with 
pathologically proven PSP have been described, including a family harboring an MAPT p.S285R mutation [24].

Other genetic or environmental factors can probably modify neurodegenerative features in human tauopathies. The H1 MAPT haplotype increases PSP risk and has been associated with higher expression of $4 \mathrm{R}$ tau, but it is too common in the general population to explain the unusual $4 \mathrm{R}$ tau predominance in the present family [25-27] and has previously been shown not to influence the phenotype of FTDP-17 patients with other MAPT mutations [28]. A more complex interaction between the R406W mutation and other genetic variability in the $\mathrm{H} 1 / \mathrm{H} 2$ clades cannot be excluded. It has also been shown that the pathology of PSP changes with regard to disease duration [29], and in AD, the predominance of either the $4 R$ or $3 R$ isoform of tau pathology similarly depends on disease duration; however, more $4 \mathrm{R}$ tau was present in early than in late AD stages [30].

Aggregation of tau and subsequent atrophy in our R406W patients was most pronounced in the VMTL area. The transentorhinal region is also prominently affected by tau pathology with NFT accumulation in early idiopathic $\mathrm{AD}$, and additional findings overlap between $\mathrm{AD}$ and FTDP-17 $7_{\mathrm{R} 406 \mathrm{~W}}$, including clinical symptoms, expression of all isoforms of tau with laboratory findings of a $3 R / 4 R$ ratio close to 1 , ultrastructural composition of tau in paired helical filaments, with a minority of short filaments [4, 31-35]. Furthermore, R406W mutated tau has been shown to increase its toxicity in the presence of $A \beta$ [36]. The locus coeruleus may be an even earlier starting point for tau pathology in AD [37] and was severely affected by tau pathology in patients III-3 and III-6. A $\beta$ pathology was found in five FTDP$17_{\text {R406W }}$ patients, four of whom had neuritic plaques ([4-6]; ZKW, personal communication). Interestingly, $A \beta$ levels have been shown to be increased to just below the plaque formation threshold in the brains of patients with FTD with MAPT mutations [38]. NFT formation in the VMTL is also a hallmark in primary age-related tauopathy (PART), formerly named tangleonly dementia. A $\beta$ deposition is believed never to ensue in PART [35], which is presumed to be a more purely age-related NFT pathology [39], but its role as an entity distinct from $\mathrm{AD}$ is debated [40, 41]. Despite the many similarities between FTDP-1 $7_{\mathrm{R} 406 \mathrm{~W}}$ and $\mathrm{AD}$, our understanding is that FTDP-17 $17_{\mathrm{R} 406 \mathrm{~W}}$ tauopathy is more clearly distinct from AD than PART is, owing to the genetic basis of the disease. The above-mentioned similarities might thus imply dual pathogenic mechanisms rather than comorbidity.

\section{Conclusions}

FTDP-17 $17_{\text {R }}$ o6w is a distinct disease entity that clinically shares features with AD, but in a novel Swedish family we found it to be associated with PSP-like, predominant $4 \mathrm{R}$ tau pathology, most pronounced in the VMTL, and we found a persistent and characteristic imaging pattern of VMTL atrophy. This disease provides an interesting model for the pathomechanisms of tau pathogenesis in humans.

\section{Additional files}

Additional file 1: Figure S1. Additional neuropathology. Additional photomicrographs from three family members. Individuals, immunohistochemistry, and enlargement as indicated. (TIF 11179 kb)

Additional file 2: Table S1. MAPT haplotype determination based on exome sequencing data. Individuals, residues, and haplotype as indicated. Note that the proband, individual III-2, had Alzheimer's disease and was excluded from the study. (PDF $181 \mathrm{~kb}$ )

Additional file 3: Table S2. Individual data from previous publications (systematic review). Numbers indicate disease duration at first reported or observed symptom. Data in parentheses are successive or vaguely specified development or data unspecifically described. *Symptoms reported by patient or relative. "Unreliable data owing to possible pharmacological cause (neuroleptics). ${ }^{\S}$ Data too imprecisely reported to be included in calculations. AD Alzheimer's disease, MCI Mild cognitive impairment, Dementia NOS Dementia not otherwise specified, CSF Cerebrospinal fluid, $A \beta_{42}$ Amyloid- $\beta$ 1-42, APOE Apolipoprotein E, ADL ACtivities of daily living. (PDF $161 \mathrm{~kb}$ )

Additional file 4: Table S3. Cerebrospinal fluid examinations. Numbers in parentheses indicate disease duration when cerebrospinal fluid was retrieved. Upward filled triangles $=$ value above laboratory's reference value for healthy individuals; downward filled triangles = value below laboratory's reference value for healthy individuals. ${ }^{a}$ Compared with healthy control subjects $(157 \pm 65 \mathrm{pg} / \mathrm{ml}, n=24)$ and patients with AD $(555 \pm 248 \mathrm{pg} / \mathrm{ml}, n=31) .{ }^{b}$ Compared with healthy control subjects ( $29 \pm$ $10 \mathrm{pg} / \mathrm{ml}, n=21)$ and patients with $A D(86 \pm 39 \mathrm{pg} / \mathrm{ml}, n=31)$. N/A Not assessed. (PDF $304 \mathrm{~kb}$ )

\section{Abbreviations}

3R tau: Three-repeat (exon 10-) tau isoform; 4R tau: Four-repeat (exon 10+) tau isoform; $A \beta$ : Amyloid- $\beta$; $A D$ : Alzheimer's disease; $A D L$ : Activities of daily living; AoO: Age of onset; APOE: Apolipoprotein E; BK: Bradykinesia; BS: Behavioral symptoms; BVFTD: Behavioral variant frontotemporal dementia; CA: Cornu ammonis; CBD: Corticobasal degeneration; CERAD: Consortium to Establish a Registry for Alzheimer's Disease; ChEl: Cholinesterase inhibitor; Comp: Compulsive repetition of words; CS: Collateral sulcus; CSF: Cerebrospinal fluid; CT: Computed tomography; DD: Duration of disease; Dementia NOS: Dementia not otherwise specified; Depr: Depression; Dis: Disinhibition; DP: Diffuse plaques; DV: Déjà vu-like experiences (i.e., spontaneously recognizing an unknown place or person); EO: Early onset; EOAD: Early-onset Alzheimer's disease; Flu: Reduced verbal fluency or output; FTD: Frontotemporal dementia; FTDP-17: Frontotemporal dementia with Parkinsonism linked to chromosome 17; LB: Lewy bodies; Lol: Loss of insight; MCl: Mild cognitive impairment; MRI: Magnetic resonance imaging; Mut: R406W heterozygote; (Mut): Obligate carrier of R406W; NFT: Neurofibrillary tangle; NP: Neuritic plaques; NT: Neutrophil threads; Para: Paraphasias; PART: Primary agerelated tauopathy; PB: Pick bodies; Pdel: Paranoid delusions; Pers: Perseverations; PET: Positron emission tomography; PHF: Paired helical filaments;

PHG: Parahippocampal gyrus; PR: Primitive reflexes; PSP: Progressive supranuclear palsy; Q: qualitative impairment; SD: Semantic dementia; SF: Straight filaments; T: Tremor; VMTL: Ventromedial temporal lobe

\section{Acknowledgements}

We thank the members of the family described for their participation in this study. We thank research nurses Christin Karremo, Emma Pettersson, and Katarina Johansson, Lund, Sweden, for coordinating patient visits. This study was partially supported by Governmental funding for clinical research within the Swedish National Health Services (ALF), Bundy Academy, MultiPark - a strategic research environment at Lund University, the Swedish Parkinson Foundation (Parkinsonfonden), Hans-Gabriel and Alice Trolle-Wachtmeister 
Foundation for Medical Research, Lions Research Fund Skåne, and Skåne University Hospital Research Foundation, all in Sweden.

\section{Funding}

This study was partially funded by Governmental funding for clinical research within the Swedish National Health Services (ALF), Bundy Academy, MultiPark - a strategic research environment at Lund University, the Swedish Parkinson Foundation (Parkinsonfonden), Hans-Gabriel and Alice Trolle-Wachtmeister Foundation for Medical Research, Lions Research Fund Skåne, and Skåne University Hospital Research Foundation, all in Sweden.

\section{Availability of data and materials}

All data generated or analyzed during this study are included in this published article and its supplementary information files.

\section{Authors' contributions}

LG originally conceived of, coordinated, and obtained funding for the study. AP continued the coordination of the study, obtained further funding, and contributed vital reagents. EY and AP developed the design of the study, interpreted data, and drafted and continuously revised the manuscript, with revisions for intellectual content provided by all other authors. RR performed the genetic studies. DVW reevaluated the radiological investigations. IA performed and helped to interpret the tau isoform analyses. EE performed all other parts of the neuropathological examinations. EY, KN, CN, MLW, LG, OH, and AP collected clinical data. ZKW obtained ethical approval and established material transfer agreements between sites. All authors read and approved the final manuscript.

\section{Ethics approval and consent to participate}

This study was performed in accordance with the ethical standards of the regional ethical review board in Lund, Sweden (LU 38-00 and 2016/294), and the institutional review board at Mayo Clinic (for genetic analyses), as well as with the 1964 Helsinki declaration and its later amendments. Written informed consent was obtained from all included members of the family who were alive in 2014 or from relatives of deceased family members included in this study.

\section{Consent for publication}

Written informed consent included publication of clinical details and was obtained from all affected family members or relatives who were alive in 2014. A copy of the consent form is available for review by the Editor-in-Chief of this journal.

\section{Competing interests}

EY has received travel grants from the Elsa Schmitz Foundation, Lund, Sweden. ZKW is partially supported by National Institutes of Health (NIH)/National Institute of Neurological Disorders and Stroke (NINDS) grant P50 NS072187 and NIH/ National Institute on Aging (primary) and NIH/NINDS (secondary) grant 1U01AG045390-01A1; the Mayo Clinic Center for Regenerative Medicine; the Mayo Clinic Center for Individualized Medicine; the Mayo Clinic Neuroscience Focused Research Team (Cecilia and Dan Carmichael Family Foundation and the James C. and Sarah K. Kennedy Fund for Neurodegenerative Disease Research at the Mayo Clinic in Florida); a gift from Carl Edward Bolch, Jr., and Susan Bass Bolch; the Sol Goldman Charitable Trust; and Donald G. and Jodi P. Heeringa. OH has acquired research support (for the institution) from Roche, GE Healthcare, Biogen, Avid Radiopharmaceuticals, Fujirebio, and Euroimmun. In the past 2 years, $\mathrm{OH}$ has received consultancy/speaker's fees (paid to the institution) from Eli Lilly and Co., Roche, and Fujirebio. AP has participated in educational activities financed by manufacturers of botulinum toxin (without receiving salary or reimbursement); has received reimbursement for travel from $H$. Lundbeck $A B$, Sweden; has received a lecturing fee from Medtronic $A B$, Sweden; has received consultancy fees from the Swedish Board of National Health and Welfare for contributions to National Treatment Guidelines for Parkinson Disease; receives research funding from the Swedish Parkinson Foundation (Parkinsonfonden), Governmental funding for clinical research within the Swedish National Health Services (ALF-YF); from MultiPark - a strategic research environment at Lund University; the Swedish Parkinson Academy; Lions Research Fund, Skåne; and Bundy Academy, Sweden. The other authors declare that they have no competing interests.

\section{Publisher's Note}

Springer Nature remains neutral with regard to jurisdictional claims in published maps and institutional affiliations.

\section{Author details}

'Lund University, Skåne University Hospital, Department of Clinical Sciences Lund, Neurology, Getingevägen 4, 22185 Lund, Sweden. ²und University, Skåne University Hospital, Department of Clinical Sciences Lund, Diagnostic Radiology, Getingevägen 4, 22185 Lund, Sweden. 'Lund University, Skåne University Hospital, Department of Clinical Sciences Lund, Oncology and Pathology, Sölvegatan 23, 22185 Lund, Sweden. ${ }^{4}$ Department of Neuroscience, Mayo Clinic, 4500 San Pablo Road, Jacksonville, FL 32224, USA. ${ }^{5}$ Department of Neurology, Mayo Clinic, 4500 San Pablo Road, Jacksonville, FL 32224, USA. 'Lund University, Skåne University Hospital/Ängelholm Hospital, Department of Clinical Sciences Lund, Memory Clinic, Västersjögatan 10, 26282 Ängelholm, Sweden. 7Department of Immunology, Genetics and Pathology, Clinical and Experimental Pathology, Uppsala University, Rudbecklaboratoriet, 75185 Uppsala, Sweden. ${ }^{8}$ Lund University, Department of Clinical Sciences Malmö, Clinical Memory Research Unit, Lund, Sweden. ${ }^{9}$ Memory Clinic, Skåne University Hospital, 20502 Malmö, Sweden.

Received: 18 September 2017 Accepted: 1 December 2017

Published online: 09 January 2018

\section{References}

1. Kovacs GG. Invited review: neuropathology of tauopathies: principles and practice. Neuropathol Appl Neurobiol. 2015;41(1):3-23.

2. Ghetti B, Oblak AL, Boeve BF, Johnson KA, Dickerson BC, Goedert M. Invited review: frontotemporal dementia caused by microtubule-associated protein tau gene (MAPT) mutations: a chameleon for neuropathology and neuroimaging. Neuropathol Appl Neurobiol. 2015;41(1):24-46. A published correction appears in Neuropathol Appl Neurobiol. 2015;41(4):571.

3. Hirschbichler ST, Erro R, Batla A, Bhatia KP. Classic PD-like rest tremor associated with the tau p.R406W mutation. Parkinsonism Relat Disord. 2015;21(8):1002-4.

4. Lindquist SG, Holm IE, Schwartz M, Law I, Stokholm J, Batbayli M, et al. Alzheimer disease-like clinical phenotype in a family with FTDP-17 caused by a MAPT R406W mutation. Eur J Neurol. 2008;15(4):377-85.

5. Rosso SM, Kamphorst W, Ravid R, van Swieten JC. Coexistent tau and amyloid pathology in hereditary frontotemporal dementia with tau mutations. Ann N Y Acad Sci. 2000;920:115-9.

6. Ishida C, Kobayashi K, Kitamura T, Ujike H, Iwasa K, Yamada M. Frontotemporal dementia with parkinsonism linked to chromosome 17 with the MAPT R406W mutation presenting with a broad distribution of abundant senile plaques. Neuropathology. 2015;35(1):75-82.

7. Scheltens P, Fox N, Barkhof F, De Carli C. Structural magnetic resonance imaging in the practical assessment of dementia: beyond exclusion. Lancet Neurol. 2002;1(1):13-21.

8. Fazekas F, Chawluk JB, Alavi A, Hurtig HI, Zimmerman RA. MR signal abnormalities at 1.5 T in Alzheimer's dementia and normal aging. AJR Am J Roentgenol. 1987;149(2):351-6.

9. Smith R, Puschmann A, Scholl M, Ohlsson T, van Swieten J, Honer $M$, et al. ${ }^{18} \mathrm{~F}-\mathrm{AV}$-1451 tau PET imaging correlates strongly with tau neuropathology in MAPT mutation carriers. Brain. 2016;139(Pt 9):2372-9.

10. Reed LA, Grabowski TJ, Schmidt ML, Morris JC, Goate A, Solodkin A, et al. Autosomal dominant dementia with widespread neurofibrillary tangles. Ann Neurol. 1997:42(4):564-72.

11. Carney RM, Kohli MA, Kunkle BW, Naj AC, Gilbert JR, Zuchner S, et al. Parkinsonism and distinct dementia patterns in a family with the MAPT R406W mutation. Alzheimers Dement. 2014;10(3):360-5.

12. Tolboom N, Koedam EL, Schott JM, Yaqub M, Blankenstein MA, Barkhof F, et al. Dementia mimicking Alzheimer's disease owing to a tau mutation: CSF and PET findings. Alzheimer Dis Assoc Disord. 2010;24(3):303-7.

13. Ng AS, Sias AC, Pressman PS, Fong JC, Karydas AM, Zanto TP, et al. Youngonset frontotemporal dementia in a homozygous tau R406W mutation carrier. Ann Clin Transl Neurol. 2015;2(12):1124-8.

14. Behnam M, Ghorbani F, Shin JH, Kim DS, Jang H, Nouri N, et al. Homozygous MAPT R406W mutation causing FTDP phenotype: a unique instance of a unique mutation. Gene. 2015;570(1):150-2.

15. Ygland E, Taroni F, Gellera C, Caldarazzo S, Duno M, Soller M, et al. Atypical Friedreich ataxia in patients with FXN p.R165P point mutation or comorbid hemochromatosis. Parkinsonism Relat Disord. 2014;20(8):919-23.

16. Moulin CJ. Disordered recognition memory: recollective confabulation. Cortex. 2013;49(6):1541-52. 
17. Wood R, Moodley K, Hodges JR, Allinson K, Spillantini MG, Chan D. Slowly progressive behavioural presentation in two UK cases with the R406W MAPT mutation. Neuropathol Appl Neurobiol. 2016;42(3):291-5.

18. Davies RR, Halliday GM, Xuereb JH, Kril JJ, Hodges JR. The neural basis of semantic memory: evidence from semantic dementia. Neurobiol Aging. 2009:30(12):2043-52.

19. van Swieten JC, Stevens M, Rosso SM, Rizzu P, Joosse M, de Koning I, et al Phenotypic variation in hereditary frontotemporal dementia with tau mutations. Ann Neurol. 1999;46(4):617-26.

20. Pickering-Brown SM, Rollinson S, Du Plessis D, Morrison KE, Varma A Richardson AM, et al. Frequency and clinical characteristics of progranulin mutation carriers in the Manchester frontotemporal lobar degeneration cohort: comparison with patients with MAPT and no known mutations. Brain. 2008;131(Pt 3):721-31.

21. Whitwell JL, Jack Jr CR, Boeve BF, Senjem ML, Baker M, Ivnik RJ, et al. Atrophy patterns in IVS10 + 16, IVS10 + 3, N279K, S305N, P301L, and V337M MAPT mutations. Neurology. 2009;73(13):1058-65.

22. Dickson DW, Ahmed Z, Algom AA, Tsuboi Y, Josephs KA. Neuropathology of variants of progressive supranuclear palsy. Curr Opin Neurol. 2010;23(4):394-400

23. Kovacs GG, Ferrer I, Grinberg LT, Alafuzoff I, Attems J, Budka H, et al. Agingrelated tau astrogliopathy (ARTAG): harmonized evaluation strategy. Acta Neuropathol. 2016;131(1):87-102.

24. Fujioka S, Sanchez Contreras MY, Strongosky AJ, Ogaki K, Whaley NR, Tacik PM, et al. Three sib-pairs of autopsy-confirmed progressive supranuclear palsy. Parkinsonism Relat Disord. 2015;21(2):101-5.

25. Myers AJ, Pittman AM, Zhao AS, Rohrer K, Kaleem M, Marlowe L, et al. The MAPT $\mathrm{H} 1 \mathrm{C}$ risk haplotype is associated with increased expression of tau and especially of 4 repeat containing transcripts. Neurobiol Dis. 2007;25(3):561-70.

26. Rademakers R, Melquist S, Cruts M, Theuns J, Del-Favero J, Poorkaj P, et al. Highdensity SNP haplotyping suggests altered regulation of tau gene expression in progressive supranuclear palsy. Hum Mol Genet. 2005;14(21):3281-92.

27. Yokoyama JS, Karch CM, Fan CC, Bonham LW, Kouri N, Ross OA, et al. Shared genetic risk between corticobasal degeneration, progressive supranuclear palsy, and frontotemporal dementia. Acta Neuropathol. 2017; 133(5):825-37.

28. Baba Y, Tsuboi Y, Baker MC, Uitti RJ, Hutton ML, Dickson DW, et al. The effect of tau genotype on clinical features in FTDP-17. Parkinsonism Relat Disord. 2005;11(4):205-8.

29. Josephs KA, Mandrekar JN, Dickson DW. The relationship between histopathological features of progressive supranuclear palsy and disease duration. Parkinsonism Relat Disord. 2006;12(2):109-12.

30. Hara M, Hirokawa K, Kamei S, Uchihara T. Isoform transition from four-repeat to three-repeat tau underlies dendrosomatic and regional progression of neurofibrillary pathology. Acta Neuropathol. 2013;125(4):565-79.

31. Miyasaka T, Morishima-Kawashima M, Ravid R, Heutink P, van Swieten JC, Nagashima K, et al. Molecular analysis of mutant and wild-type tau deposited in the brain affected by the FTDP-17 R406W mutation. Am J Pathol. 2001;158(2):373-9.

32. Hong $M$, Zhukareva $V$, Vogelsberg-Ragaglia V, Wszolek Z, Reed L, Miller Bl, et al. Mutation-specific functional impairments in distinct tau isoforms of hereditary FTDP-17. Science. 1998:282(5395):1914-7.

33. de Silva R, Lashley T, Strand C, Shiarli AM, Shi J, Tian J, et al. An immunohistochemical study of cases of sporadic and inherited frontotemporal lobar degeneration using 3R- and 4R-specific tau monoclonal antibodies. Acta Neuropathol. 2006;111(4):329-40.

34. Reed LA, Wszolek ZK, Hutton M. Phenotypic correlations in FTDP-17. Neurobiol Aging. 2001;22(1):89-107.

35. Mott RT, Dickson DW, Trojanowski JQ, Zhukareva V, Lee VM, Forman M, et al. Neuropathologic, biochemical, and molecular characterization of the frontotemporal dementias. J Neuropathol Exp Neurol. 2005;64(5):420-8.

36. Tackenberg $C$, Brandt R. Divergent pathways mediate spine alterations and cell death induced by amyloid- $\beta$, wild-type tau, and R406W tau. J Neurosci. 2009;29(46):14439-50.

37. Braak H, Del Tredici K. The preclinical phase of the pathological process underlying sporadic Alzheimer's disease. Brain. 2015;138(Pt 10):2814-33.

38. Vitali A, Piccini A, Borghi R, Fornaro P, Siedlak SL, Smith MA, et al. Soluble amyloid $\beta$-protein is increased in frontotemporal dementia with tau gene mutations. J Alzheimers Dis. 2004;6(1):45-51.

39. Crary JF, Trojanowski JQ, Schneider JA, Abisambra JF, Abner EL, Alafuzoff I, et al. Primary age-related tauopathy (PART): a common pathology associated with human aging. Acta Neuropathol. 2014;128(6):755-66.
40. Duyckaerts C, Braak H, Brion JP, Buee L, Del Tredici K, Goedert M, et al. PART is part of Alzheimer disease. Acta Neuropathol. 2015;129(5):749-56.

41. Jellinger KA, Alafuzoff I, Attems J, Beach TG, Cairns NJ, Crary JF, et al. PART, a distinct tauopathy, different from classical sporadic Alzheimer disease. Acta Neuropathol. 2015;129(5):757-62.

42. Passant U, Ostojic J, Froelich Fabre S, Gustafson L, Lannfelt L, Larsson EM, et al. Familial presenile dementia with bitemporal atrophy. Dement Geriatr Cogn Disord. 2004;17(4):287-92.

43. Ikeuchi T, Imamura T, Kawase $Y$, Kitade $Y$, Tsuchiya M, Tokutake T, et al. Evidence for a common founder and clinical characteristics of Japanese families with the MAPT R406W mutation. Dement Geriatr Cogn Dis Extra. 2011;1(1):267-75.

44. Komatsu J, Ono K, Yanase D, Samuraki M, Shima K, Kuwano R, et al. Imaging findings of familial dementia with a tau R406W mutation. Acta Neurol Belg. 2011;111(4):374-5

45. Rizzu P, Van Swieten JC, Joosse M, Hasegawa M, Stevens M, Tibben A, et al. High prevalence of mutations in the microtubule-associated protein tau in a population study of frontotemporal dementia in the Netherlands. Am J Hum Genet. 1999;64(2):414-21.

46. Saito Y, Geyer A, Sasaki R, Kuzuhara S, Nanba E, Miyasaka T, et al. Early-onset, rapidly progressive familial tauopathy with R406W mutation. Neurology. 2002:58(5):811-3.

47. Ostojic J, Elfgren C, Passant U, Nilsson K, Gustafson L, Lannfelt L, et al. The tau R406W mutation causes progressive presenile dementia with bitemporal atrophy. Dement Geriatr Cogn Disord. 2004;17(4):298-301.

48. Basiri K, Ansari B, Meamar R. Frontotemporal dementia parkinsonism: clinical findings in a large Iranian family. Adv Biomed Res. 2015;4:37.

49. Wojtas A, Heggeli KA, Finch N, Baker M, Dejesus-Hernandez M, Younkin SG, et al. C9ORF72 repeat expansions and other FTD gene mutations in a clinical AD patient series from mayo clinic. Am J Neurodegener Dis. 2012; 1(1):107-18.

50. Ikeuchi T, Kaneko H, Miyashita A, Nozaki H, Kasuga K, Tsukie T, et al. Mutational analysis in early-onset familial dementia in the Japanese population: the role of PSEN1 and MAPT R406W mutations. Dement Geriatr Cogn Disord. 2008;26(1):43-9.

51. Kitade Y, Sato A, Imamura T. Two sibling patients with Alzheimer's disease associated with presenile onset and very slowly progressive clinical course. Jpn J Neuropsychol. 2006;22:260-8.

52. Rademakers $R$, Dermaut $B$, Peeters $K$, Cruts M, Heutink P, Goate A, et al. Tau (MAPT) mutation Arg406Trp presenting clinically with Alzheimer disease does not share a common founder in Western Europe. Hum Mutat. 2003; 22(5):409-11.

53. Perry DC, Whitwell JL, Boeve BF, Pankratz VS, Knopman DS, Petersen RC, et al. Voxel-based morphometry in patients with obsessive-compulsive behaviors in behavioral variant frontotemporal dementia. Eur J Neurol. 2012; 19(6):911-7.

\section{Submit your next manuscript to BioMed Central and we will help you at every step:}

- We accept pre-submission inquiries

- Our selector tool helps you to find the most relevant journal

- We provide round the clock customer support

- Convenient online submission

- Thorough peer review

- Inclusion in PubMed and all major indexing services

- Maximum visibility for your research

Submit your manuscript at www.biomedcentral.com/submit
) Biomed Central 